\title{
MONITORING THE PETERMANN ICE ISLAND WITH TANDEM-X
}

\author{
José A. García ${ }^{1}$, Kevin Eyssartier ${ }^{2}$, Paco López-Dekker ${ }^{1}$, Pau Prats ${ }^{1}$, Francesco De Zan ${ }^{1}$, \\ Gerhard Krieger ${ }^{1}$ and Thomas Busche ${ }^{1}$ \\ ${ }^{1}$ German Aerospace Center, Microwave and Radar Institute, Oberpfaffenhofen, Germany \\ ${ }^{2}$ Institute National Polytechnique de Grenoble, Grenoble, France
}

\begin{abstract}
This paper presents the processing of TanDEM-X acquisitions for the monitoring of the topography of the Petermann ice island. In this particular case the area under study is continuously moving and the acquisition geometry is changing, so the processing of the iceberg's DEMs is challenging and additional effects are to be considered. The SAR processing chain used is presented and the results obtained summarized, showing the effects and limitations observed during the process.
\end{abstract}

Index Terms - TanDEM-X, DEM, iceberg, Radon

\section{INTRODUCTION}

In August 2010 the head of the Petermann glacier, located in Greenland, broke into a $250 \mathrm{~km}^{2}$ iceberg. The goal of the work presented in this paper is to study the evolution of this iceberg, in particular the changing topography due to melting, based on a time-series of TanDEM-X interferometric SAR images [1,2]. The main challenge in the processing of the available acquisitions is the large scale motion of the iceberg, which is drifting and rotating. Figure 1 shows a picture of the iceberg on August 16, 2010, 11 days after the calving.

For the monitoring of the iceberg, 9 pairs of SAR images acquired with the TanDEM-X system between August 25, 2010 and September 14, 2010 are available. It has to be noticed that different acquisition geometries are considered in order to increase the number of images available during this period. The iceberg is not completely covered in all the acquisitions. Moreover, it broke in half between the $8^{\text {th }}$ and the $11^{\text {th }}$ of September. Table 1 shows some details about 4 of the TanDEM-X system acquisitions used in the next sections.

\section{DATA PROCESSING}

The process applied to the SAR data is summarized in the flow chart depicted in Figure 2. The interferometric SAR processing of each pair of images is performed with the

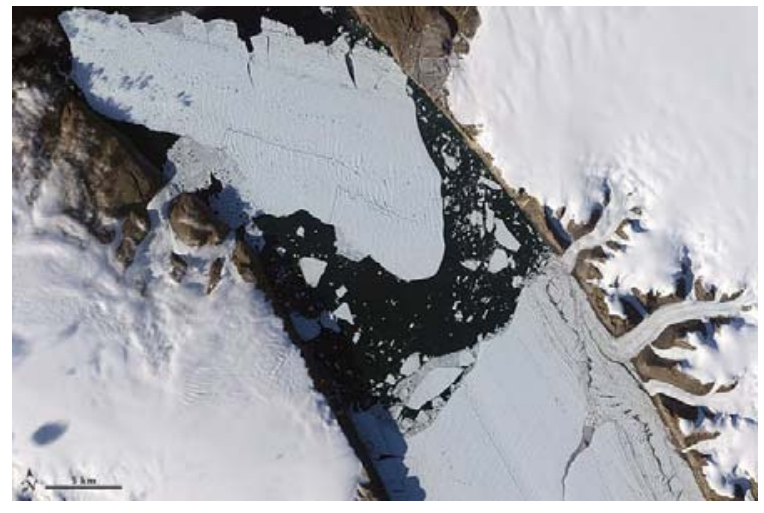

Figure 1: Natural-color image of the Petermann ice island on August 16, 2010 captured by the EO-1 ALI satellite (NASA)

\begin{tabular}{|c|c|c|c|}
\hline Acq. & Date & $\begin{array}{c}\text { Baseline } \\
{[\mathrm{m}]}\end{array}$ & $\begin{array}{c}\text { Height of } \\
\text { ambiguity [m] }\end{array}$ \\
\hline 1 & $25 / 08 / 2010$ & 193.9 & 40.4 \\
\hline 2 & $31 / 08 / 2010$ & 184.1 & 39.2 \\
\hline 3 & $02 / 09 / 2010$ & 148.6 & 33.9 \\
\hline 4 & $05 / 09 / 2010$ & 197.1 & 39.8 \\
\hline
\end{tabular}

Table 1: Acquisitions used to summarize the results

TAXI tool developed by DLR [3]. In this particular case, the rotational fringes introduced on the interferometric phase by the iceberg rotation have to be removed before the phase unwrapping [4,5]. The interferometric phase introduced by a rotation angle as function of the azimuth position $X$ from the center of mass of the iceberg can be defined as [5]

$$
\phi_{\text {rot }}(x)=\frac{4 \pi}{\lambda} x \sin \theta_{\text {rot }} \sin \theta_{\text {inc }}
$$

where $\theta_{r o t}$ is the iceberg rotation angle and $\theta_{i n c}$ is the local incidence angle. Additionally, a region growing algorithm is applied as well at this level to limit the region of interest to be further processed. Figure 3 shows an example of the azimuth fringes present on the Petermann ice island.

Once the geocoded DEMs are obtained for each acquisition, an alignment process is applied in order to be 


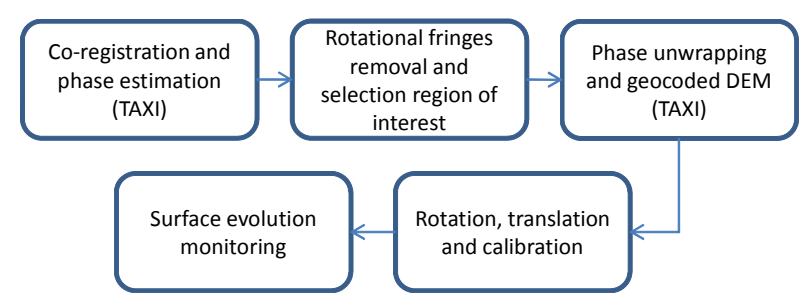

Figure 2: SAR data processing flow chart

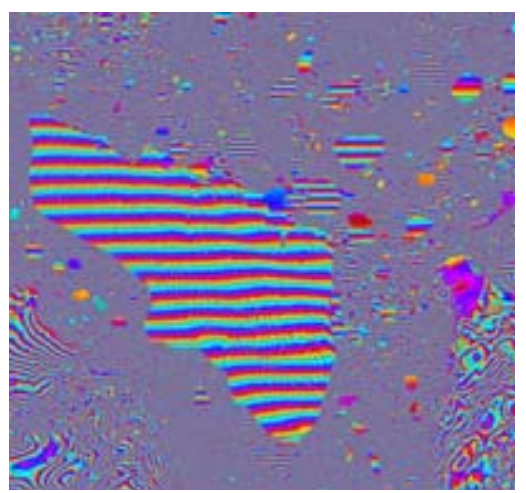

Figure 3: Rotational fringes on the Petermann ice island

able to monitor the melting on the iceberg surface. The goal is to align the iceberg's height information applying translation and rotation operations. This process is repeated through all the available images for comparison. For this purpose, and due to the large scale rotations, the Radon transform [6] is used. The usage of the Radon transform can be of special interest when the image to be processed contains line components (which are represented as dots in the Radon domain). Therefore, it is interesting to perform the Radon transform of the DEMs' $2 \mathrm{D}$ derivative in order to enhance the changes in the iceberg surface (i.e. those changes are used as reference). An example of the iceberg's surface derivative in the Radon domain is shown in Figure 4. Taking a pair of DEMs to be aligned, and once the Radon transform is applied, a 2D correlation of the obtained images in the Radon domain is performed. The maximum of the resulting correlation function marks the rotation to be applied to align the icebergs on both DEMs. Additionally, the drifts are corrected based on the 2D correlation of the DEMs. This dual process is performed iteratively until the icebergs of both DEMs are aligned. Figure 5 shows an example of two aligned DEMs.

Before comparing the height information, several remarks are to be considered. First, it has to be noticed that the DEMs' heights are relative values, so absolute measurements are not available for comparison. Second, the removal of the rotational fringes, which is necessary for the correct generation of the DEMs, could be removing a slope component in the azimuth direction, so the DEMs could be tilted. And last, the iceberg is continuously moving, so extra height variations could be introduced (e.g. an extra slope).
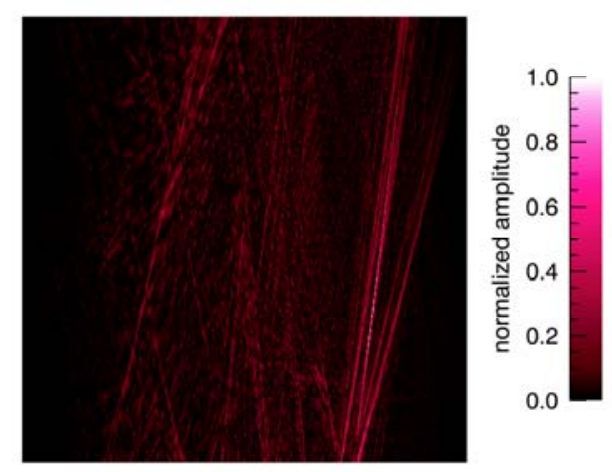

Figure 4: Example of the iceberg's surface derivative in the Radon domain
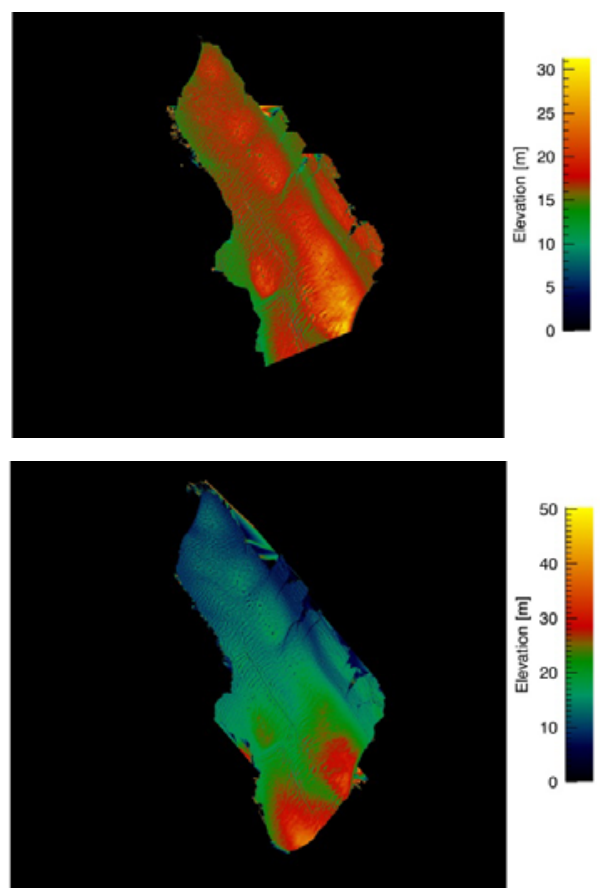

Figure 5: DEMs after alignment process (acquisitions on August 25 and August 31, 2010)

Therefore, a compensation of these effects is required before performing the height comparison. For this purpose, the 2D slope of the DEMs is removed.

\section{RESULTS}

Figure 6 shows the height difference between two acquisitions (taken on August 25 and August 31, 2010) before and after the slope compensation. It is clear that the height alignment is needed in order to properly monitor the surface changes. On the other hand, it can be appreciated that some artifacts are present in the height differences which could be induced by a 3D misalignment.

In order to remove those artifacts the height difference is low pass filtered. Figure 7 shows the results obtained when comparing acquisitions from the $31^{\text {st }}$ of August and 

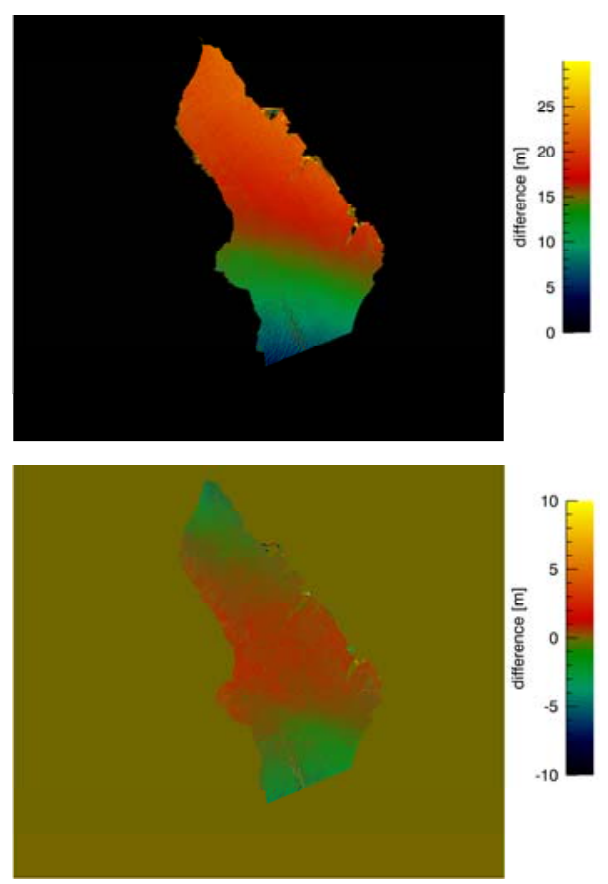

Figure 6: Height difference (between August 25 and August 31, 2010) before and after slope compensation, respectively
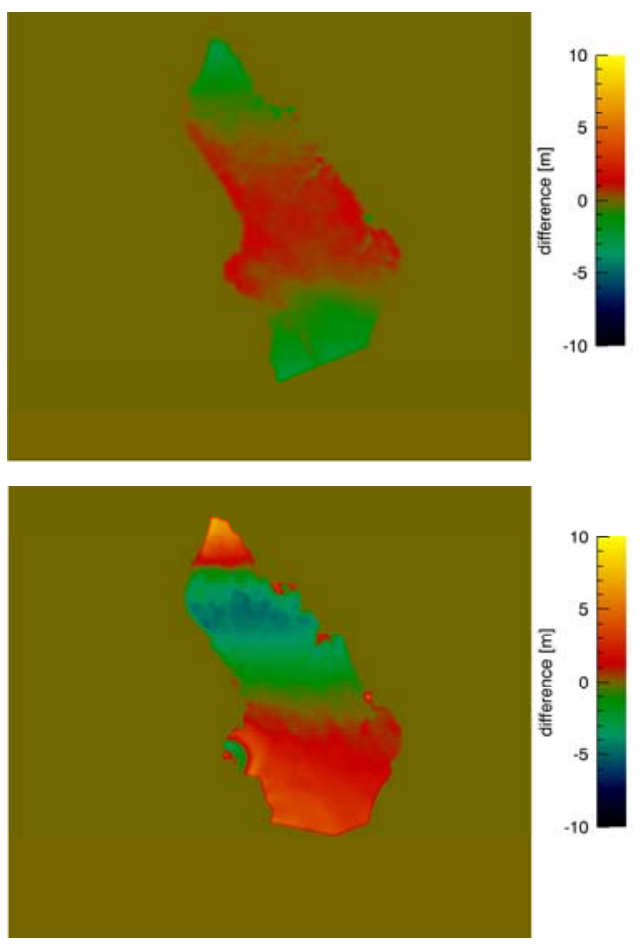

Figure 7: Smoothed height difference between August 25 and August 31, 2010 (top image) and August 25 and September 2, 2010 (bottom image)

the $2^{\text {nd }}$ of September to the first acquisition on the $25^{\text {th }}$ of August. In the images, a clear height variation pattern can
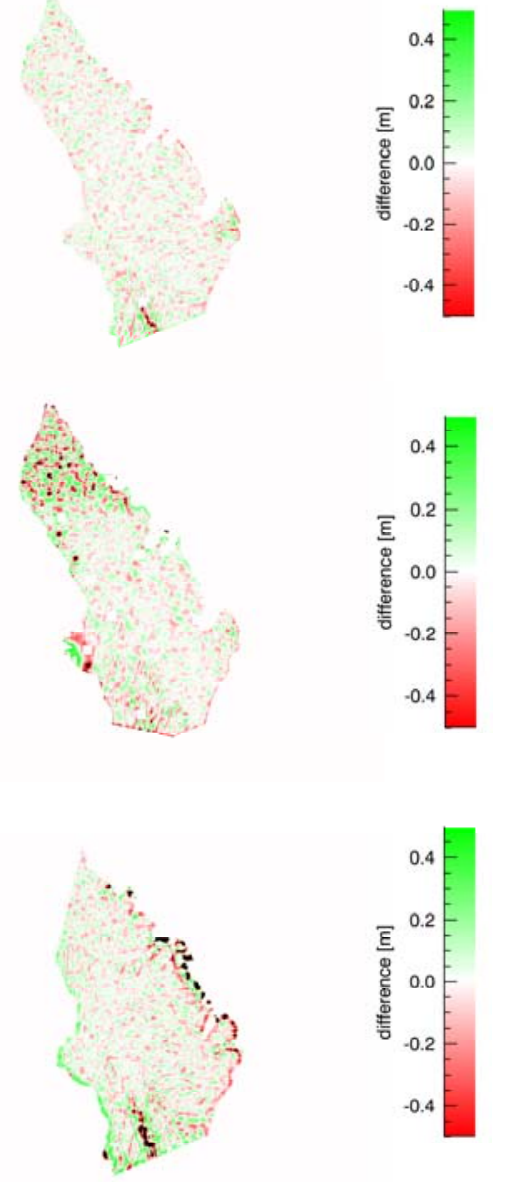

Figure 8: Band pass filtered height differences (top: acq. 2-1; center: acq. 3-1; bottom: acq. 4-1)

be observed in the vertical direction. Nevertheless, the variation is not the same for both comparisons since an opposite pattern behavior is observed. Therefore, these components cannot in principle be introduced by a topographic change but by an unknown effect which could be originated in the geocoded DEMs generation after the rotational fringes removal. In the following, this second order height component is to be removed $\left(1^{\text {st }}\right.$ order height slope is already removed). As result, the band pass filtered height differences are the ones used for the evaluation of the surface changes.

Figure 8 shows the filtered height differences of acquisitions 2 to 4 in Table 2 w.r.t. the first acquisition, which is taken as a reference. A detail of the height differences in the center of the iceberg, where data are available for the 3 comparisons, is depicted in Figure 9 (3x1 $\mathrm{km}^{2}$ area shown). Additionally, a 1D comparison of the height differences is depicted in Figure 10 (a horizontal line of pixels in the center of the iceberg is used). It can be observed that there exists a certain correlation in the change evolution between the images, although it is also clear that there could be still remaining artifacts which make difficult 


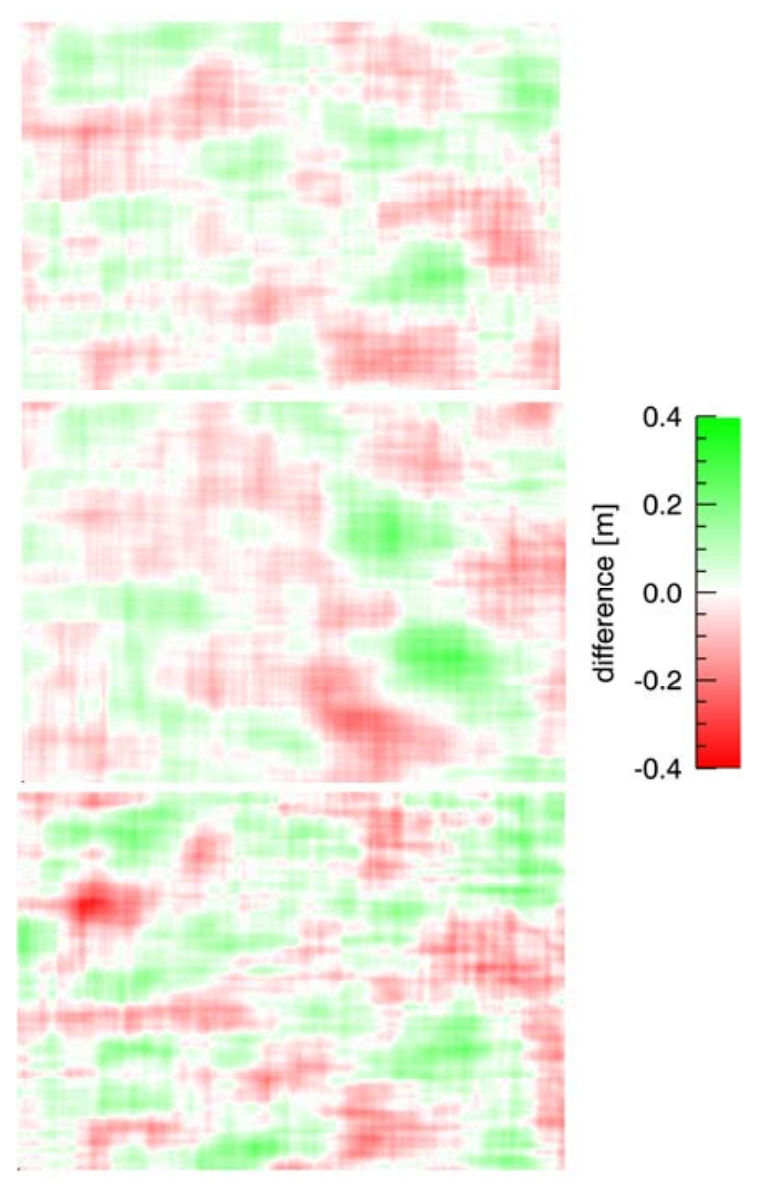

Figure 9: Detail of Figure 7 in the center of the iceberg (3x1 km² area; top: acq. 2-1; center: acq. 3-1; bottom: acq. 4-1)

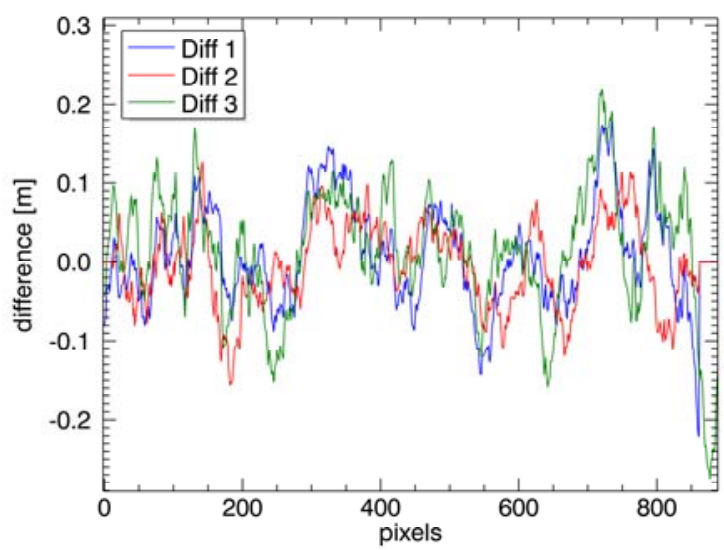

Figure 10: 1D detail of Figure 7 in the center of the iceberg (diff1: acq. 2-1; diff2: acq. 3-1; diff3: acq. 4-1)

the monitoring of the evolution. On top of this, it has to be noticed that the process performed is equivalent to a $3 \mathrm{D}$ alignment of the DEMs where $1^{\text {st }}$ and $2^{\text {nd }}$ order height effects are filtered, so only relative variations can be evaluated and some topographic change components could be being removed.

\section{CONCLUSIONS}

The monitoring of the surface topography of a moving area like the Petermann ice island is a challenging task. First, rotational fringes are to be considered in the DEMs' generation. Second, for the estimation of the height differences between DEMs big rotations are to be corrected. And finally, only relative values are available and $1^{\text {st }}$ and $2^{\text {nd }}$ order height effects are to be considered. This makes the surface monitoring difficult, as shown in the results presented in this paper, since unknown effects could be impacting the height differences and still some artifacts are present.

\section{ACKNOWLEDGMENT}

The results presented in this paper have been gained using SAR images granted by DLR in response to the prelaunch TanDEM-X science proposal CALVAL_0061.

\section{REFERENCES}

[1] A. Moreira, G. Krieger, I. Hajnsek, D. Hounam, M. Werner, S. Riegger, and E. Settelmeyer, "TanDEM-X: A TerraSAR-X add-on satellite for single-pass SAR interferometry”, in Proc. IGARSS, 2004, pp. 1000-1003

[2] G. Krieger, A. Moreira, H. Fiedler, I. Hajnsek, M. Werner, M. Younis, and M. Zink: "TanDEM-X: A Satellite Formation for High-Resolution SAR Interferometry”, IEEE Trans. Geosci. Remote Sens., vol. 45, no. 11, pp. 3317-3341, November, 2007.

[3] P. Prats, M. Rodriguez-Cassola, L. Marotti, M. Nannini, S. Wollstadt, D. Schulze, N. Tous-Ramon, M. Younis, G. Krieger, A. Reigber, "Taxi: A versatile processing chain for experimental TanDEM-X product evaluation”, in Proc. IGARSS, 2010, pp. 4059-4062

[4] M. Thomas, M. Steffens, and R. Roth: "Measuring changes of iceberg attitudes by SAR interferometry", Proc. of 3rd ERS symposium, Florence, 1997

(http://earth.esa.int/workshops/ers97/papers/thomas1/)

[5] R. Scheiber, F. De Zan, P. Prats, L. Sant'Anna Araujo, M. Künemund, L. Marotti, "Interferometric Sea Ice Mapping with TanDEM-X: First Experiments”, in Proc. IGARSS, 2011, pp. 3594-3597

[6] J.S. Lim, Two-Dimensional Signal and Image Processing, Englewood Cliffs, NJ, Prentice Hall, pp. 42-45, 1990 